\title{
AUTOGENOUS TOOTH TRANSPLANTATION IN ADULT OROFACIAL CLEFT DEFORMITY: A CASE REPORT
}

\author{
*B. E. Edetanlen, C.C. Azodo, P.E. Egbor, O. Akpata
}

*Department of Oral and Maxillofacial Surgery, University of Benin Teaching Hospital Benin City, Nigeria

\section{Correspondence:}

Dr B. E. Edetanlen

Department of Oral and Maxillofacial Surgery, University of Benin Teaching Hospital

P.M.B. 1111 Ugbowo

Benin City, Nigeria

Email: ehiben2002@yahoo.com

\section{ABSTRACT}

A case of autotransplantation of a tooth in a 26 year old female African cleft palate patient is reported.

This case report emphasizes the possibility and success of autotransplantation in our centre, it also emphasizes that transplantation is only technique sensitive but less equipment sensitive. It further stresses that an otherwise extracted and discarded tooth can be used to make natural functional unit.

Keyword: autotransplantation, tooth, cleft palate, success, technique sensitive, extraction.

\section{INTRODUCTION}

Autogenous tooth transplantation or autotransplantation is the surgical movement in one individual of a vital or endodontically treated tooth from its original location in the mouth to another site. ${ }^{1}$ The earliest report of tooth transplantation involves slaves in ancient Egypt who were forced to give their teeth to their pharaohs ${ }^{2}$. Autogenous tooth transplantation was first well documented in 1954 by M.L Hale. ${ }^{3}$ This technique seems superior to allotransplantation because of less problem of histocompatibility. $2,4-8$

Autotransplantation has previously been viewed with uncertainty because of lack of information on the topic and poor clinical results of reported cases.9-12 These poor results were due to a lack of understanding of the biological principles involved and poor clinical technique. ${ }^{9-12,13}$

Another barrier to the acceptance of the technique has been the misconception that autotransplantion can only be successful when immature, developing teeth are transplanted. ${ }^{14}$

Success of autotransplantion is viewed in terms of survival, with or without root filling.

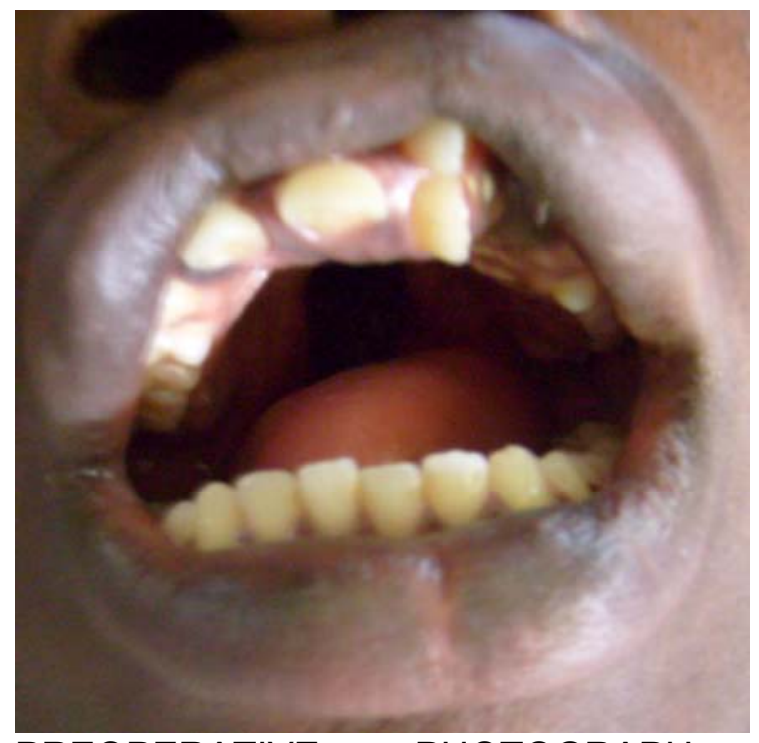

PREOPERATIVE PHOTOGRAPH 


\section{CASE REPORT}

A 26 year old black African female presenting to our oral and maxillofacial surgery department of University of Benin Teaching Hospital Benin City with complains of poor speech and nasal reflux of liquid and food. She added that she had cleft lip repair 10 years back but she is not comfortable with the outcome of the repair because the upper lip is wider than the lower lip. She was also psychological disturbed on account of the arrangement of the maxillary anterior teeth.

On examination, she had widened upper lips with two vertical prominent philtral scars. The lips were incompetent. She had bilateral centric occlusion. In the anterior segment, there were asymmetric spacing, mesiobuccal displacement and mesiopalatal rotation of the left maxillary lateral incisor. The left central incisor was also palatally displaced and mesiopalatally rotated. She also had midline shift.

Preoperative periapical radiograph was taken to assess the roots of the left maxillary central and lateral incisors but the root were normal and closed.

Orthodontic treatment was advised but she opted for extraction due to cost. She further stressed that her upper lip size is her prime concern.

She was prepared for cleft lip revisit surgery and cleft palate repair. The cleft lip was repaired using Veau 111 method and the cleft palate was repaired using Von Langerbeck technique

On recall back, she was happy for the outcome of the repair but opted for extraction of the malaligned anterior teeth. Then an option of autotransplantion was explained to the patient and she agreed to undergone the procedure.

Using routine local anaesthesia infiltration, and under aseptic technique, the left maxillary central and lateral incisors were extracted carefully to avoid root fracture. The maxillary central incisor was kept in normal saline as a storage medium. Then the alveoli socket was widened using surgical bur on a hand piece connected to a rotor motor under jet spray using normal saline. Then the stored maxillary central incisor was reimplanted and held in place by a composite splinting.

She was then placed on saline mouth bath with antibiotics.

On recall visit, the implanted tooth was examined for mobility and this was absent. Then the composite splint was removed. Serial postoperative periapical radiograph were taken (6weeks and 6 months) and this shows normal anatomy.

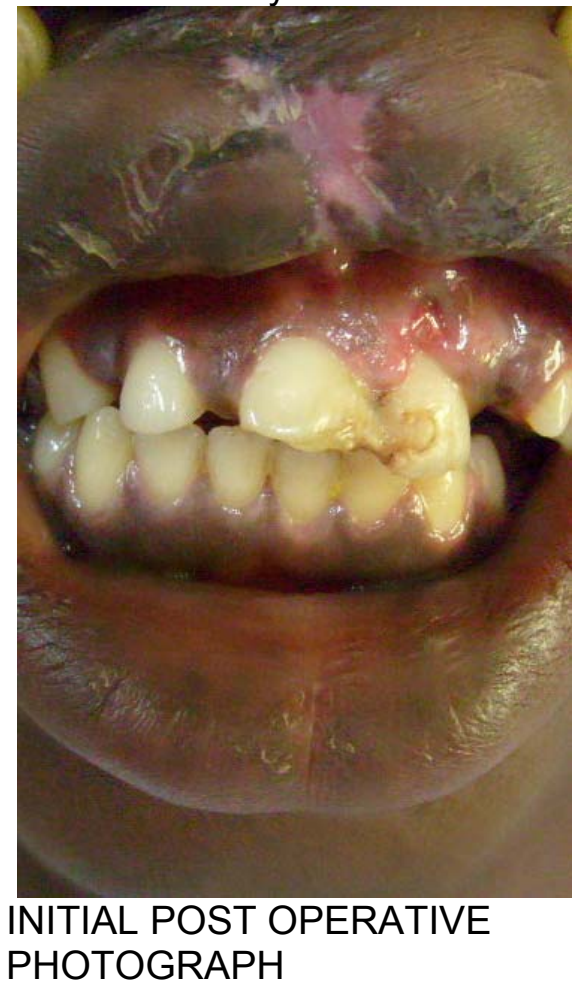
PHOTOGRAPH 


\section{DISCUSSION}

This study shows that auto-transplant can be done in all ages. It also shows that auto transplant is a successful procedure if done under aseptic condition and it can be a normal routine procedure if required by patient. More so, it is not equipment sensitive procedure. It only requires that the recipient cavity is wide enough not to disturb the periodontal tissues. It can also be done in a tooth with closed apex unlike where previous reports asserted that it is only successful in an open apex tooth. It can also serve an alternative for extraction and replacement with prosthetics which is known to have some limitations. More so, this case report just demonstrates that the tooth that would otherwise have been extracted or left within bone can be used to make biologically functioning units.

The factors that led to success have been extensively investigated. The most significant determinant for survival of the transplant is the continued vitality of the periodontal membrane ${ }^{15}$. Schwartz tried to link loss of the graft to specific prognostic factors and found that the success rates are higher when donor teeth are anterior teeth, have one-half to twothirds root development, experience minimal trauma and limited extra oral time during surgery ${ }^{16}$. The experience of the surgeons also affects the success because this procedure is technique but not equipment sensitive.

Although retention of a tooth and restoration of the edentulous space is the desired outcome for patient, more specific parameters have been used to measure the health of surviving transplant ${ }^{17}$. These parameters include marginal periodontal attachment mobility, pain, root resorption, root development, sensitivity to percussion, gingival pocket depth, presence of gingivitis and presence of fistula ${ }^{18}$.

The most common cause of failure of auto transplant is chronic root resorption ${ }^{19}$. More specifically, the causes of tooth loss following transplantation from most common to least common are inflammatory resorption, replacement resorption (ankylosis), marginal periodontitis, apical periodontitis, caries and trauma. Inflammatory resorption may become evident after 3 or 4 weeks while replacement resorption may not become evident until 3 or 4 month after transplant ${ }^{20}$. The incidence of both types of resorption can be decreased with atraumatic extraction of the donor tooth and immediate transfer to the recipient site to minimize the risk of injury to the periodontal ligament ${ }^{21}$

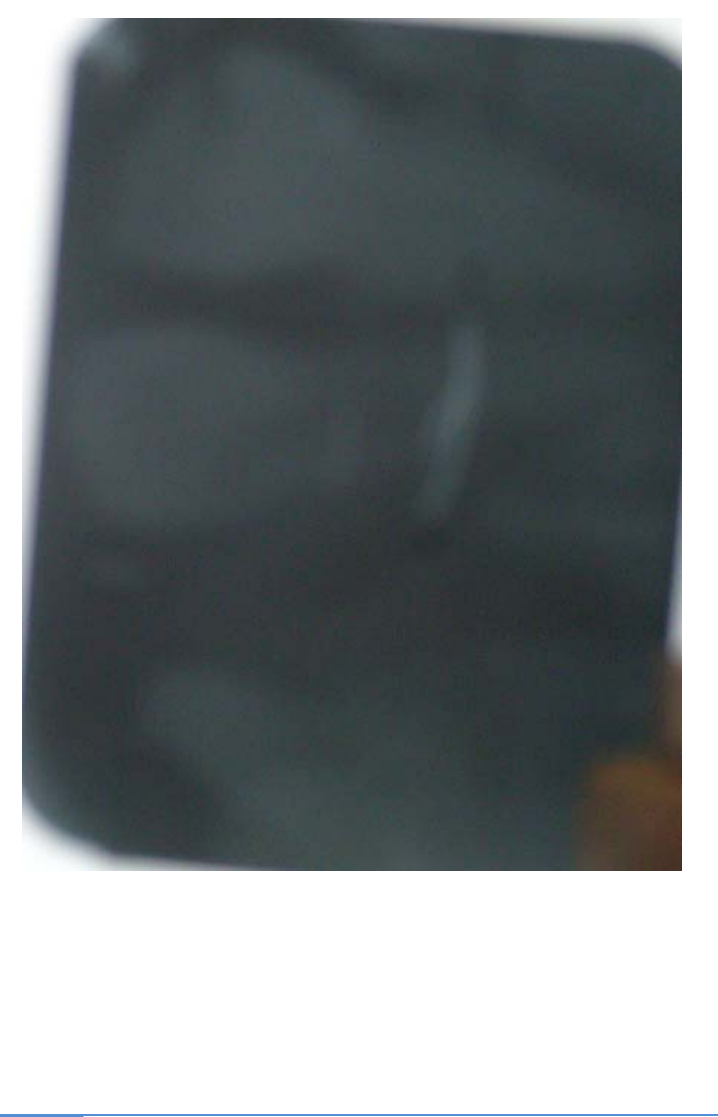




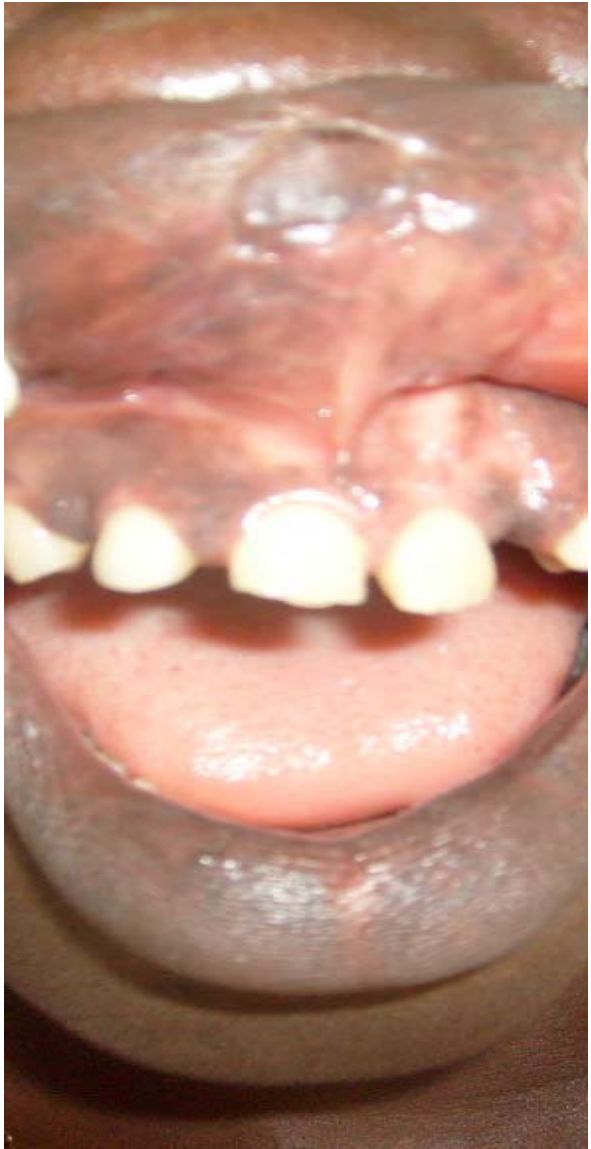

$6^{\text {th }}$ MONTH POST OPERATIVE PHOTOGRAPH

\section{REFERENCES}

1. Leffingwell $\mathrm{CM}$. Autogenous tooth transplantation: a therapeutic alternative. Dent Surv 1980; 56(2):22-3, 26.

2. Cohen AS, Shen TC, Pogrel MA. Transplanting teeth successfully: autografts and allografts that work. JADA 1995; 126(4):481-5.

3. Hale ML. Autogenous transplants. Oral Surg Oral Med Oral Pathol 1956; 9:76-83.

4. Nethander G. Periodontal conditions of teeth autogenously transplanted by a two-stage technique. J Periodontal Res 1994; 29(4):250-8.
5. Andreasen JO, Paulsen HU, Yu Z, Bayer T, Schwartz O. A long-term study of 370 autotransplanted premolars. Part II. Tooth survival and pulp healing subsequent to transplantation. Eur J Orthod 1990; 12(1):14-24.

6. Lundberg T, Isaksson S. A clinical follow-up study of 278 autotransplanted teeth. $\mathrm{Br} \mathrm{J}$ Oral Maxillofac Surg 1996; 34(2):181-5.

7. Kugelberg R, Tegsjo U, Malmgren O. Autotransplantation of 45 teeth to the upper incisor region in adolescents. Swed Dent J 1994; 18(5):165-72.

8. Josefsson E, Brattstrom V, Tegsjo $\mathrm{U}$, Valerius-Olsson $\mathrm{H}$. Treatment of lower second premolar agenesis by autotransplantation: four-year evaluation of eighty patients. Acta Odontol Scand 1999; 57(2):111-5.

9. Kahnberg KE. Autotransplantation of teeth: indications for transplantation with a follow-up of 51 cases. Int J Oral Maxillofac Surg 1987; 16(5):577-85.

10. Tegsjo $U$, Valerius-Olsson $H$, Frykholm A, Olgart K. Clinical evaluation of intra-alveolar transplantation of teeth with cervical root fractures. Swed Dent J 1987; 11(6):235-50.

11. Kristerson L, Lagerstrom L. Autotransplantation of teeth in cases with agenesis or traumatic loss of maxillary incisors. Eur $\mathrm{J}$ Orthod 1991; 13(6):486-92.

12. Northway WM, Konigsberg S. Autogenic tooth transplantation: the 
"state of the art". Am J Orthod 1980; 77(2):146-62.

13. Pogrel MA. Evaluation of over 400 autogenous tooth transplants. J Oral Maxillofac Surg 1987; 45(3):205-11.

14. Akiyama $\mathrm{Y}$, Fukuda $\mathrm{H}$, Hashimoto K. A clinical and radiographic study of 25 autotransplanted third molars. J Oral Rehabil 1988; 25(8):640-4.

15. Robinson PJ, Grossman LI. Tooth Transplantation. In: Robinson PJ, Guernsey LJ, eds. Clinical transplantation in dental specialties. St. Louis: C.V. Mosby Co.; 1980. p. 77-88.

16. Schwartz O, Bergmann P, Klausen B. Autotransplantation of human teeth: a life-table analysis of prognostic factors. Int J Oral Surg 1985; 14(3):245-58.

17. Andreasen JO, Paulsen HU, Yu Z, Ahlquist R, Bayer T, Schwartz O. A long-term study of 370 autotransplanted premolars. Part I. Surgical procedures and standardized techniques for monitoring healing. Eur $\mathrm{J}$ Orthod 1990; 12(1):3-13.

18. Tsukiboshi M. Autogenous tooth transplantation: a reevaluation. Int $J$ Periodontics Restorative Dent 1993; 13(2):120-49.

19. Andreasen JO, Paulsen HU, Yu Z, Schwartz $O$. A long-term study of 370 autotransplanted premolars. Part III. Periodontal healing subsequent to transplantation. Eur J Orthod 1990; 12(1):25-37.

20. Andreasen JO, Paulsen HU, Yu Z, Bayer T. A long-term study of 370 autotransplanted premolars. Part IV. Root development subsequent to transplantation. Eur $\mathrm{J}$ Orthod 1990; 12(1):38-50.

21. Smith DE, Zarb GA. Criteria for success of osseointegrated endosseous implants. J Prosthet Dent 1989; 62(5):567-72.

22. Thomas S, Turner SR, Sandy R. Autotransplantation of teeth: is there a role? $\mathrm{Br} \mathrm{J}$ Orthod 1998; 25(4):275-82. 